\title{
Post Liver Transplantation Survival and Related Prognostic Factors among Adult Recipients in Tehran Liver Transplant Center; 2002-2019
}

\author{
Elham Madreseh, PhD Candidate'; Mahmood Mahmoudi, PhD'; Mohssen Nassiri-Toosi, MD²; Taban Baghfalaki, PhD³; Hojjat Zeraati, PhD ${ }^{*}$ \\ 'Department of Epidemiology and Biostatistics, School of Public Health, Tehran University of Medical Sciences, Tehran, Iran \\ ${ }^{2}$ Liver Transplantation Research Center, Imam Khomeini Hospital Complex, Tehran University of Medical Sciences, Tehran, Iran \\ ${ }^{3}$ Department of Statistics, Faculty of Mathematics sciences, Tarbiat Modares University, Tehran, Iran
}

\begin{abstract}
Background: Liver transplantation is a standard treatment for patients with end-stage liver disease (ESLD). However, with increasing demand for this treatment and limited resources, it is available only to patients who are more likely to survive. The primary aim was to determine prognostic factors for survival.

Methods: We collected data from 597 adult patients with ESLD, who received a single organ and initial orthotopic liver transplantation (OLT) in our center between 20 March 2008 and 20 March 2018. In this historical cohort study, univariate and multiple Cox model were used to determine prognostic factors of survival after transplantation.

Results: After a median follow-up of 825 (0-3889) days, 111 (19\%) patients died. Survival rates were 88\%, 85\%, 82\% and 79\% at 90 days, 1 year, 3 years, and 5 years, respectively. Older patients ( $\mathrm{HR}=1.27 ; 95 \% \mathrm{Cl}: 1.01-1.59$ ), presence of pre-OLT ascites $(\mathrm{HR}=2.03 ; 95 \% \mathrm{Cl}: 1.16-3.57)$, pre-OLT hospitalization $(\mathrm{HR}=1.88 ; 95 \% \mathrm{Cl}: 1.02-3.46)$, longer operative time $(\mathrm{HR}=1.006$; 95\% Cl: $1.004-1.008)$, post-OLT dialysis (HR $=3.51 ; 95 \% \mathrm{Cl}: 2.07-5.94)$, cancer (HR $=2.69 ; 95 \% \mathrm{Cl}: 1.23-5.89)$ and AID (HR $=2.04 ; 95 \% \mathrm{Cl}: 1.17-3.56)$ as underlying disease versus hepatitis, and higher pre-OLT creatinine ( $\mathrm{HR}=1.67 ; 95 \% \mathrm{Cl}: 1.10-2.52)$ were associated with decreased survival.

Conclusion: In this center, not only are survival outcomes excellent, but also younger patients, cases with better pre-operative health conditions, and those without complications after OLT have superior survival.

Keywords: Ascites, Dialysis, Hepatocellular carcinoma, Tehran Liver Transplant Center

Cite this article as: Madreseh E, Mahmoudi M, Nassiri-Toosi M, Baghfalaki T, Zeraati H. Post liver transplantation survival and related prognostic factors among adult recipients in Tehran Liver Transplant Center; 2002-2019. Arch Iran Med. 2020;23(5):326334. doi: 10.34172/aim.2020.22.
\end{abstract}

Received: August 22, 2019, Accepted: January 26, 2020, ePublished: May 1, 2020

\section{Introduction}

End-stage liver disease (ESLD) is categorized into two main subgroups: acute liver failure (ALF) and chronic liver disease or cirrhosis. The former is a rare and rapidly progressive disorder, whereas the latter is a more common condition, causing damage to liver over time. ${ }^{1}$

ESLD is extremely costly in terms of human suffering, medical visits, and premature loss of productivity. The incidence of ESLD is increasing and in the absence of liver transplantation, it confers a very high fatality rate worldwide every year. ${ }^{2}$

Orthotopic liver transplantation (OLT) using donation after brain death, was initially reported in 1963 by Thomas Starzl. ${ }^{3}$ After the discovery of the immunosuppressant cyclosporine in 1971 and the agreement seminar organized by the US National Institute of Health in 1983, liver transplantation (LT) was accepted as a standard treatment for ESLD. ${ }^{4}$ LT provides excellent long-term survival, and improves the quality of life and professional activities. ${ }^{5,6}$
In Iran, the national program for LT was commenced in Shiraz in 1993, ${ }^{7}$ and in 2002 in Tehran Liver Transplant Center (TLTC). Since 2005, all hospital-based costs are covered by the government for all Iranian patients, but costs related to immunosuppressive drugs after liver transplant are not covered by any health insurance.

In 2016, the annual rate of deceased LT was estimated to be 6.39 per million population worldwide; the United States and China, with the largest number of transplants, i.e. 7496 and 3264, respectively, ranked first and second. ${ }^{8}$ Also, Iran's contribution, as the ninth country in the world and the first in the Middle East, was 770 liver transplants. ${ }^{8}$ These transplants have been done at eight centers, but most of them had fewer than 100 patients per year.

TLTC is located at the Imam Khomeini Hospital Complex, the first LT center in Tehran (the capital of Iran), and the second largest in Iran; and it operates under the supervision of Tehran University of Medical Sciences. The first liver transplant in TLTC was performed in 
2002. So far, more than 700 consecutive LTs have been carried out by the same retrieval and transplant team with minimal changes in the composition and roles of the team members. The center volume is increasing; 128 transplants were performed in 2016 only and this number has been higher every year since then. According to a published article by Macomber et al, LT programs with more than 75 LTs per year were considered as a high-volume transplant centers, had lower morbidity and mortality rates than lower-volume centers, and were also more cost-efficient. ${ }^{9}$ Therefore, TLTC is considered a high-volume transplant center.

According to the data of the International Registry in Organ Donation and Transplantation, in Iran, like most countries, liver is the most common transplant organ after the kidney. In 2017, 33.5\% of the deceased donors were assigned to LT - a significant increase compared to $17.1 \%$ in 2002 . Also, the demand for this organ has increased from 0.7 per million population in 2002 to 11.43 in $2017 .{ }^{10}$ Therefore, with increasing demand for LT and limited resources, it is available only to patients who are more likely to survive, given a set of characteristics at the time of transplantation. Some scoring systems have been developed based on such characteristics for creating patient lists for LT.

Transplant success is evaluated through patient survival as the most common outcome. Survival rates range from $79.5 \%$ to $84.6 \%$ during the first year, and $65 \%$ to $79.1 \%$ at five years after transplantation. ${ }^{8}$ The survival rates for recipients from deceased donors in Shiraz were $74.0 \%$ at 1 year and $70.0 \%$ at 5 years. ${ }^{11}$ Improving the outcomes of transplantation is not only related to graft dysfunction, but also, depends on modifiable factors associated with late mortality. ${ }^{12,13}$ According to research findings, several sets of factors affect the survival of LT patients including recipient and organ donor characteristics, transplant center-related factors and sociocultural and economic factors. ${ }^{14-20}$

Despite improvements in surgical techniques and postoperative care, including availability of immunosuppressant drugs, more research is still necessary on the factors associated with short- and long-term outcomes for optimal use of the donated organs in the Iranian population. The current investigation analyzes nearly one decade of experience by the same team in a single center. In this center, the model for End-Stage Liver Disease (MELD) scoring system was used for organ allocation. ${ }^{21}$ As a prevailing criterion, it provides donor organs to listed recipients with the highest estimated short-term mortality before LT. ${ }^{22-24}$

In the current study, short- and medium-term outcomes of OLT, and factors affecting survival are analyzed. Also, the incidence and scope of post-OLT complications are determined.

\section{Materials and Methods}

Patients

In this single-center historical cohort study, the information of all patients undergoing OLT was collected from their medical records. All recipients younger than 18 years old $(n=27)$, re-transplantation patients $(n=38)$, and combined transplant patients $(n=6)$ were excluded from the study. As the first 6 years of TLTC were considered as an establishment period for the transplant team, the patient information from this period was not included in the analyses $(\mathrm{n}=14)$. In total, 597 adult patients who received a single organ and initial OLT in TLTC between 20 March 2008 and 20 March 2018 were included in the analyses (Figure 1). All patients were followed by regular visits or phone calls until death or the end of the study period (20 January 2019). Right censoring occurs when a subject leaves the study before death occurs, or the study

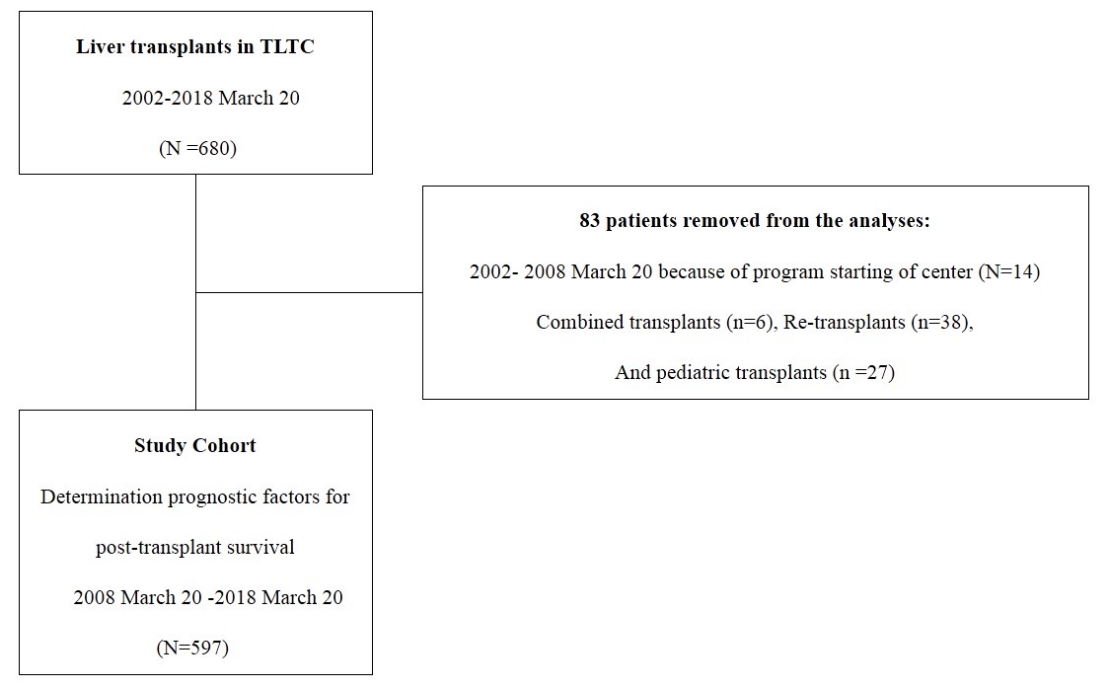

Figure 1. Flow Diagram Showing the Patients in the Study Defined Cohorts. TLTC: Tehran Liver Transplant Center. 
ends before the event has occurred. Patients who were lost to follow-up were considered as right censoring at their last visit date $(\mathrm{n}=33)$. Therefore, the starting point of the patient's survival analysis was the time of the LT, while the patient's death, last visit or end of study were considered as the endpoint.

\section{Study Endpoints}

Primary endpoints were overall survival after LT and the evaluation of related prognostic factors. Secondary endpoints were to determine the incidence and scope of postoperative complications such as cause of death, recurrence, rejection, renal failure, dialysis, and CMV infection.

\section{Variables}

Recipient, donor, laboratory, operative, and postoperative variables that were obtained from our database and had no missing, or $<15 \%$ missing data, were used. Acute cellular rejection was diagnosed based on histologic criteria. Diabetes mellitus (DM) was defined as a diagnosis that required treatment with insulin or oral hypoglycemic drugs. Renal failure was defined as serum creatinine $\geq$ $2 \mathrm{mg} / \mathrm{dL} .{ }^{13}$ The MELD equation used to calculate the severity score was as follows ${ }^{25}$ :

\section{Meld $=9.6 \times \ln ($ creatinin $(\mathrm{mg} / \mathrm{dl}))+11.2 \times \ln (\mathrm{INR})+$ $3.8 \times \ln (\operatorname{bilirubin}(m g / d l))+6.43$}

The Child-Pugh scorewas evaluated using five parameters: ascites, encephalopathy, bilirubin, prothrombin time and albumin. ${ }^{26}$ We adopted an 8-category liver disease classification system and definitions similar to that used by Roberts et al. ${ }^{27}$

Ascites was detected by sensitive imaging studies such as ultrasonography and physical examination. Furthermore, encephalopathy was defined as appearance of signs of occasional forgetfulness, insomnia or distorted sleep pattern. ${ }^{28}$ Details about surgical procedures and their related factors in TLTC are provided in previous reports. ${ }^{29}$

According to annual liver data reports, ${ }^{30}$ we used the 5-category cause of death among deceased liver donors including: anoxia, cerebrovascular accident, head trauma, central nervous system tumor and other causes.

\section{Statistical Analysis}

Categorical variables were summarized as frequencies (percentages). Continuous variables were described as median (range), or mean $( \pm S D)$. Missing values were imputed by the Markov chain Monte Carlo method, allowing for arbitrary missing data patterns. Reverse Kaplan-Meier method was applied to estimate the median survival time. Kaplan-Meier estimates were used to calculate survival curves.

All considered factors were tested using univariate and multiple Cox proportional hazard (PH) analysis. All variables that were significant in the univariate model $(P<0.25)$ or those clinically important were entered into the multiple model. A stepwise approach based on improvement in Akaike's information criterion (AIC) was used for variable selection. ${ }^{31}$

$\mathrm{PH}$ assumption was tested using independence between the scaled Schoenfeld residuals and time. To determine whether any of the continuous variables exhibited nonlinearity, the Martingale residuals test was used. According to the results obtained in this test, some variables were log transformed (INR, bilirubin, creatinine) and some were squared (age). ${ }^{32}$ The prognostic accuracy of the final model was calculated using time-dependent/dynamic area under receiver operating characteristic curves [AUROC (t)]. Statistical significance was set at 0.05. All statistical analyses were performed using the R3.4.0 statistical software.

\section{Results}

Recipients, Donors and Perioperative Characteristics The mean waiting time for transplant was $318 \pm 451$ days. The male to female ratio of patients and donors was 1.5:1 and 2.03:1, respectively. The mean \pm SD age of recipients and their BMI at transplant was $45 \pm 12$ years and 25 $\pm 4 \mathrm{~kg} / \mathrm{m}^{2}$. Moreover, 24\%, 30\%, 45\%, and $1 \%$ of the patients were 18-34 years, 35-49 years, 50-64 years, and $\geq 65$ years old, respectively. The median donor age for these age groups of recipients was 31 years, 34 years, 36 years, and 37 years, respectively $(P=0.079)$.

Most patients had blood group A (36.2\%) and $\mathrm{O}$ (35.2\%). Overall, $74 \%$ of transplanted patients had no comorbidity before LT. Only $12 \%$ of patients were hospitalized before LT; however, $76 \%$ of them had ascites.

The mean \pm SD of MELD scores was $20.5 \pm 5.6$, and patients were classified into four groups according to their MELD at transplant. Respectively, $6 \%$ and $7 \%$ of the patients had MELD scores $<15$ and $>30$. Categorization of the patients based on the CHILD scoring system showed that $4 \%, 34 \%$, and $62 \%$ of the patients were in class $\mathrm{A}, \mathrm{B}$, and $\mathrm{C}$, respectively.

The most common indications for OLT were autoimmune and cryptogenic cirrhosis (AID, 38\%), hepatitis B virus (HBV, 11\%), hepatitis C virus ( $\mathrm{HCV}$, $11 \%$ ), primary sclerosing cholangitis (PSC, 10\%), metabolic liver disease (9\%), cancer (7\%), ALF (5\%), primary biliary cirrhosis (PBC, 3\%), and other liver diseases (4\%) in adults.

The patients' clinical presentation at the time of transplant was different, and they were mostly not in the hospital at the time of transplant (88\%).

Regarding the donors, the most common causes of brain death were head trauma (45\%), cerebrovascular accident/ stroke $(29 \%)$, anoxia $(6 \%)$, central nervous system tumor $(3 \%)$, others rare causes $(6 \%)$ and unknown causes $(12 \%)$. 
Most donors were male (69\%). The mean \pm SD duration of brain death and length of stay in ICU were $4 \pm 3$ days and $5.5 \pm 4$ days, respectively.

The mean \pm SD duration of operation, cold and warm ischemic times were $230 \pm 80,295 \pm 66$ and $27 \pm 17$ minutes, correspondingly. More summaries are shown in Table 1.

In TLTC, the number of LTs increased from 13 in 2008 to 102 in 2017; however, the average waiting time was 470 \pm 557 and $350 \pm 481$ days, respectively (Figure 2). This decrease was not statistically significant $(P=0.205)$. Also, the most common cause of transplantation in 2008 and 2017 was hepatitis and autoimmune/epithelial diseases, respectively

Complications, Survival Outcomes and Related Factors The mean duration of post-transplant hospitalization was
$15 \pm 10$ days. Moreover, 421 (71\%) of the patients showed at least one early or late complication, such as acute cellular rejection [181 (31\%)], CMV infection [149 (26\%)], diabetes complication [114 (19\%)], renal complication [207 (36\%)], dialysis [43 (7\%)], and recurrence [68 (11\%)] after the transplantation, while no complications were found in $176(29 \%)$ patients.

After a median follow-up of 825 (0-3889) days, 111 (19\%) patients died due to early or late complications and rejection; of those, $60 \%$ were male. The most common causes of death were sepsis (36\%), recurrence $(14 \%)$, bleeding $(10 \%)$, renal failure $(5 \%)$, other related causes $(21 \%)$ and unknown causes (14\%).

It should be noted that 69 (62.2\%), 16 (14.4\%), 15 $(13.5 \%)$ and $7(6.3 \%)$ of the deaths occurred in 90 days, 1 year, 3 years and 5 years after transplantation, respectively. In the univariate analysis, donor and recipient age, pre-

Table 1. Patients' Survival Status at the End of Follow-up According to Pre-transplantation Characteristics of Recipient, Donor and Surgical Factors, Tehran Liver Transplant Center (2008-2019)

\begin{tabular}{|c|c|c|c|c|}
\hline \multirow[b]{2}{*}{ Variables, Mean \pm SD or No. $(\%)$} & \multirow{2}{*}{$\begin{array}{l}\text { All OLT } \\
n=597\end{array}$} & \multicolumn{2}{|c|}{ Survival Status } & \multirow[b]{2}{*}{ Unadjusted ${ }^{*} \mathrm{HR}(95 \% \mathrm{Cl})$} \\
\hline & & $\begin{array}{c}\text { Alive } \\
\mathrm{n}=\mathbf{4 8 6}(81 \%)\end{array}$ & $\begin{array}{c}\text { Died } \\
\mathrm{n}=111(19 \%)\end{array}$ & \\
\hline Age $(y)$ & $44.81 \pm 12.5$ & $44.34 \pm 12.53$ & $46.88 \pm 12.21$ & $1.02(1.004-1.04)$ \\
\hline Sex (male) & $356(60 \%)$ & $289(81 \%)$ & $67(19 \%)$ & $1.03(0.70-1.51)$ \\
\hline $\mathrm{BMI}\left(\mathrm{kg} / \mathrm{m}^{2}\right)$ & $25.12 \pm 4.15$ & $24.98 \pm 4.01$ & $25.71 \pm 4.69$ & $1.03(0.99-1.09)$ \\
\hline Waiting time (day) & $314 \pm 448$ & $312 \pm 445$ & $319 \pm 465$ & $1.001(0.99-1)$ \\
\hline \multicolumn{5}{|l|}{ Diseases } \\
\hline HCV/HBV (reference) & $128(21 \%)$ & $110(86 \%)$ & $18(14 \%)$ & - \\
\hline ALF & $28(5 \%)$ & $23(82 \%)$ & $5(18 \%)$ & $1.87(0.69-5.06)$ \\
\hline $\mathrm{PBC} / \mathrm{PSC}$ & $78(13 \%)$ & $67(86 \%)$ & $11(14 \%)$ & $1.07(0.50-2.27)$ \\
\hline ALD & $14(2 \%)$ & $11(79 \%)$ & $3(21 \%)$ & $1.63(0.48-5.55)$ \\
\hline AID & $227(38 \%)$ & $181(80 \%)$ & $46(20 \%)$ & $1.55(0.89-2.67)$ \\
\hline $\mathrm{HCC}$ & $42(7 \%)$ & $32(76 \%)$ & $10(24 \%)$ & $1.98(0.91-4.31)$ \\
\hline Metabolic liver disease & $54(9 \%)$ & $45(83 \%)$ & $9(17 \%)$ & $1.34(0.60-2.98)$ \\
\hline Other & $26(4 \%)$ & $17(65 \%)$ & $9(35 \%)$ & $3.58(1.60-8.0)$ \\
\hline Precondition (hospitalized) & $72(12 \%)$ & $48(67 \%)$ & $24(33 \%)$ & $2.96(1.86-4.69)$ \\
\hline Pre-creatinine $^{* *}(\mathrm{mg} / \mathrm{dL})$ & $1.07 \pm 1.40$ & $1.03 \pm 1.48$ & $1.21 \pm 1.00$ & $1.92(1.39-2.64)$ \\
\hline Pre-total bilirubin ${ }^{* *}(\mathrm{mg} / \mathrm{dL})$ & $6.55 \pm 8.33$ & $6.47 \pm 8.42$ & $6.88 \pm 8.00$ & $0.97(0.77-1.23)$ \\
\hline Pre-INR** & $1.97 \pm 0.83$ & $1.95 \pm 0.79$ & $2.06 \pm 0.96$ & $1.38(0.77-2.47)$ \\
\hline Pre-prothrombin time (s) & $18.25 \pm 4.6$ & $18.0 \pm 4.0$ & $19.19 \pm 5.0$ & $2.98(1.32-6.72)$ \\
\hline MELD score & $21 \pm 5$ & $20 \pm 5$ & $22 \pm 6$ & $1.06(1.03-1.09)$ \\
\hline Pre-ascites (yes) & $459(77 \%)$ & $364(79 \%)$ & $95(21 \%)$ & $1.83(1.07-3.13)$ \\
\hline Cytomegalovirus (yes) & $149(25 \%)$ & $128(86 \%)$ & $21(14 \%)$ & $0.68(0.42-1.11)$ \\
\hline Rejection (yes) & $181(30 \%)$ & $150(83 \%)$ & $31(17 \%)$ & $0.88(0.58-1.36)$ \\
\hline Diabetes mellitus (yes) & $114(19 \%)$ & $92(81 \%)$ & $22(19 \%)$ & $1.06(0.66-1.69)$ \\
\hline Dialysis (yes) & $43(7 \%)$ & $16(37 \%)$ & $27(63 \%)$ & $7.58(4.82-11.91)$ \\
\hline Donor sex (male) & $402(67 \%)$ & $326(81 \%)$ & $76(19 \%)$ & $1.04(0.68-1.61)$ \\
\hline Donor age (year) & $35.0 \pm 13.0$ & $34.59 \pm 12.68$ & $36.58 \pm 12.33$ & $1.01(0.99-1.03)$ \\
\hline length of stay in ICU (day) & $5.5 \pm 3.5$ & $5.0 \pm 3.0$ & $6.0 \pm 3.0$ & $1.03(0.98-1.09)$ \\
\hline Duration of brain death (day) & $4.3 \pm 3.0$ & $4.0 \pm 3.0$ & $5.0 \pm 3.0$ & $1.06(1.004-1.12)$ \\
\hline $\mathrm{CIT}(\min )$ & $295 \pm 66$ & $291 \pm 62$ & $313 \pm 77$ & $1.004(1.001-1.006)$ \\
\hline Operative time (min) & $302 \pm 80$ & $293 \pm 68$ & $344 \pm 110$ & $1.005(1.003-1.007)$ \\
\hline
\end{tabular}

OLT: orthotopic liver transplantation; HR: hazard ratio; Cl: confidence interval; BMI: body mass index; ALF: Acute liver failure; PBC: Primary biliary cirrhosis; PSC: Primary sclerosing cholangitis; ALD: Alcoholic liver disease; AID: Autoimmune and cryptogenic disease; HCV: hepatitis C virus; HBV: hepatitis B virus; HCC: hepatocellular carcinoma; INR: international normalized ratio; MELD: model of end-stage liver disease; CIT: cold ischemic time.

"Univariate cox proportional hazard model; "* In natural log scale for modeling. 


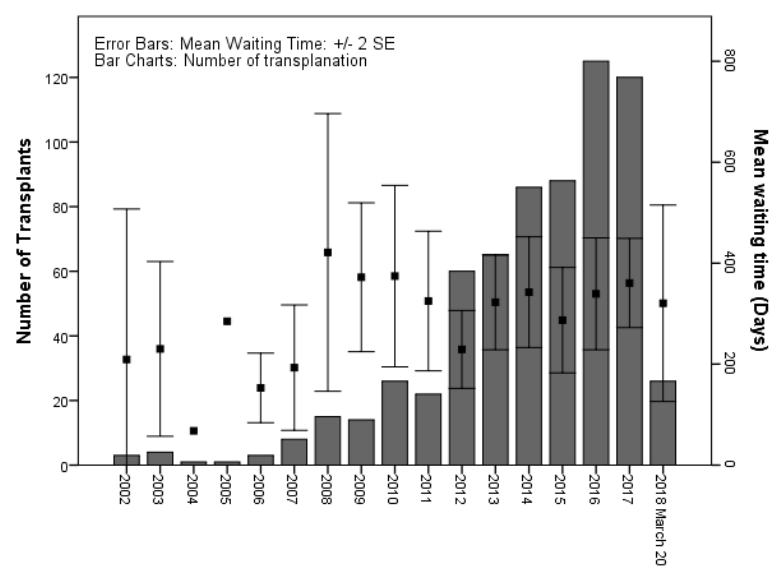

Year

Figure 2. Bar Chart Showing the Number of Liver Transplantation and Error Bar Showing the Mean Waiting Time in Tehran Liver Transplant Center from 2002 to 2018.

OLT ascites, pre-OLT condition, pre-prothrombin time, donor brain death duration, cold ischemia time, length of operation, patients' renal problems and MELD score were found to be effective factors on the patients' survival (some results are not represented). These significant variables along with those clinically important, were considered in multiple models.

In the multiple analysis of the 12 prognostic variables selected for the final Cox model, only the recipient's age (in square scale), pre-OLT ascites, pre-OLT condition, length of operation, existence of post-LT dialysis, etiology/ underlying diseases, and pre-OLT creatinine (in log scale) were the significant variables (Table 2).

The hazard of death after LT was two-fold among patients with autoimmune disease (AID) as compared with hepatitis patients $(\mathrm{HR}=2.04,95 \% \mathrm{CI}[1.17-3.56])$. Also, the hazard of death increased by $80 \%$ when patients had been hospitalized pre-OLT. The hazard ratios of those who had pre-OLT ascites and post-OLT dialysis were 2.01 and 3.51 , respectively.

The mortality rate of patients with old age, high creatinine and high operative time was higher than those with lower values. The rest of the results are presented in Table 2. Furthermore, the adjusted survival rates were estimated as: $0.88 \%$ at 90 days, $85 \%$ at 1 year, $82 \%$ at 3 years, and $79 \%$ at 5 years.

Dynamic AUC versus time under the $\mathrm{PH}$ assumption was estimated. Since the AUC values were more than 0.7 until 5 years, our final model is accurate for predicting the risk of mortality until this time. The area under the ROC curves (AUC) for predicting the risk of mortality at 1 year, 3 year and 5 years after LT was $81.08 \%, 78.48 \%$ and $71.98 \%$, respectively (results not shown).

\section{Discussion}

In the current shortage of organs for transplant, it is important to identify patients who benefit the most from
Table 2. Risk Factors for Patient Failure after Liver Transplant by the Results of Multiple Cox PH Regression Model, Tehran Liver Transplant Center; 20082019

\begin{tabular}{lccc}
\hline Variables & Adjusted HR & $\mathbf{9 5 \%} \mathbf{C l}$ & P Value $^{\mathbf{a}}$ \\
\hline Age* & 1.27 & $1.01-1.59$ & 0.038 \\
\hline Pre-ascites (yes) & 2.03 & $1.16-3.57$ & 0.014 \\
\hline Pre-condition (hospitalized) & 1.88 & $1.02-3.46$ & 0.042 \\
\hline Pre-prothrombin time** & 2.39 & $0.95-6.04$ & 0.064 \\
\hline Operative time & 1.006 & $1.004-1.008$ & $<0.001$ \\
\hline Post-dialysis (yes) & 3.51 & $2.07-5.94$ & $<0.001$ \\
\hline Diseases & & & \\
\hline HCV/HCV (reference) & - & - & - \\
\hline ALF & 2.18 & $0.69-6.89$ & 0.185 \\
\hline PBC/ PSC & 1.40 & $0.61-3.19$ & 0.427 \\
\hline ALD & 0.77 & $0.20-3.03$ & 0.712 \\
\hline AID & 2.04 & $1.17-3.56$ & 0.012 \\
\hline HCC & 2.69 & $1.23-5.89$ & 0.013 \\
\hline Metabolic Liver Disease & 2.07 & $0.92-4.69$ & 0.079 \\
\hline Other & 4.37 & $1.84-10.4$ & $<0.001$ \\
\hline Alcohol consumption history (yes) & 1.79 & $0.94-3.41$ & 0.075 \\
\hline Pre-creatinine** & 1.67 & $1.10-2.52$ & 0.016 \\
\hline Pre-comorbidity (yes) & 1.51 & $0.87-2.61$ & 0.142 \\
\hline Waiting time & 1.0004 & $1.00-1.001$ & 0.060 \\
\hline Post-diabetes mellitus (yes) & 0.64 & $0.35-1.17$ & 0.144 \\
\hline
\end{tabular}

HR: hazard ratio; $\mathrm{Cl}$ : confidence interval; $\mathrm{BMI}$ : body mass index; $\mathrm{ALF}$ : Acute liver failure; PBC: Primary biliary cirrhosis; PSC: Primary sclerosing cholangitis; ALD: Alcoholic liver disease; AID: Autoimmune and cryptogenic disease; HCV: hepatitis C virus; HBV: hepatitis B virus; HCC: hepatocellular carcinoma.

a Final multivariate cox $\mathrm{PH}$ model based on stepwise selection variable and AIC criteria; * In square scale; ** In natural log scale.

liver transplantation, and to discover the risk factors associated with poor outcome.

In this study, the effect of recipient and donor characteristics, perioperativefactorsand somecomplications on patient survival in TLTC are investigated. According to Figure 2, while the number of LTs has increased over time, the average waiting time in the TLTC has declined. This demonstrates that improvements have been made in the management of organ allocation in recent years in this center, especially after 2005 when liver transplant became free of charge for patients in Iran. Currently, the mean interval between listing and transplantation is under 400 days, which is longer than the European Liver Transplant Registry. ${ }^{33,34}$

TLTC is a well-established center in the Eastern Mediterranean region. According to our findings, short(1 year) and median-term survivals (5 years) are $89 \%$ and $84 \%$, respectively. Thus, survival after liver transplantation in TLTC is excellent, which is similar to some studies. ${ }^{33,34}$ The main findings of the final multiple Cox model represented that recipient's age, underlying diseases, preOLT ascites, precondition condition and creatinine, length of operation and post-LT dialysis were significantly related to patient survival. According to this model, other factors such as pre-OLT prothrombin time, history of 
alcohol consumption, pre-OLT comorbidity status, postLT diabetes, and waiting time to LT were not associated with survival. As the results revealed, the accuracy of this model was high.

According to similar studies, ${ }^{12,35,36}$ and our results in the univariate and multiple analysis (Table 1), recipient's age was identified as a risk factor which affects mortality after transplantation. This may be due to physiological status; therefore, diagnosing and transplanting at younger age are important in improving patient survival. So, one may consider adding age as a variable in the criteria for determining priority of transplantation. The upper age limit for patients undergoing transplantation in TLTC is 70 years; this is similar to other LT centers during the past three decades. ${ }^{37-40}$

Compared with older donors, the younger were more commonly male and traumatized. Advanced donor age was identified as a risk factor only in our univariate analysis. The death risk of patients who received liver from donors in the age group of 50-64 years was 5 times more than those under 18 years old. Therefore, the effect of aging on various organs, such as liver, reduces their functions; but with adjusting in the multiple model, donor age was not significant. This finding is in contrast with numerous previous studies which demonstrated a significantly decreased survival in recipients of older donations within a large study. ${ }^{15,17,27,35,41-43}$ Setting an appropriate cut-off point for recipients and donors age could lead to better allocations; more research is required in this regard.

In this center, the etiology of liver disease was mostly AID (38\%), while approximately one quarter of LTs performed in Europe and the United States were due to autoimmune liver diseases. ${ }^{44}$ Hepatitis (B and $\mathrm{C}$ ) was the second most common cause of transplantation in this study, while it was considered as the most common cause in some studies. ${ }^{34}$ Contrary to the Western world, ${ }^{45}$ due to religious beliefs, alcoholic liver cirrhosis was not a common indication for liver transplant in our study. Different classification of disease may have led to these various results. In the present study, the liver disease classification system used by Dawwas et al was employed. ${ }^{46}$

As other studies show, post liver transplant survival was strongly related to underlying diseases..$^{11,27,42,46,47}$ In this study, patients with autoimmune-cryptogenic cirrhosis (about 2-fold) and HCC (about 3-fold) had poorer survival compared to those with hepatitis. Since the recurrence of autoimmune liver disease after LT is prevalent and may be asymptomatic early on, biopsies could be used to prevent poor outcomes. However, hereditary background and unknown factors still exist in these individuals even after LT. These results were in contrast with some studies which demonstrated that LT was associated with excellent patient survival in subjects with autoimmune liver diseases. ${ }^{48}$

The MELD score is a controversial matter in patient survival. In most studies, MELD score was only effective on short-term survival, and it was indicated that high MELD score was an independent risk factor for poor outcomes after LT. ${ }^{11,17,49-51}$ This finding was confirmed in our univariate analysis; however, after adjusting for the effect of other variables, this score was not significant because the MELD score was valuable for identifying the patients with the worst conditions, and might not be a suitable survival predictor. Furthermore, according to previous studies, it has been shown that patient prognosis is more related to clinical parameters than laboratory data and MELD score. ${ }^{15,52,53}$

However, presence of ascites before transplant was a significant factor for post-OLT survival. Since ascites can cause hyper-fibrinolysis in advanced liver disease, ${ }^{54,55}$ and also, severe liver disease is a known risk factor for developing hyper-fibrinolysis, ${ }^{56}$ the accuracy of prediction may be increased when ascites is included in the MELD index.

The study by Horvatits et $\mathrm{al}^{57}$ showed that postoperative dialysis was associated with increased mortality after LT. Also, in our study, dialysis patients had a higher mortality rate (3.5-fold), possibly because they had more medical comorbidities. In addition, similar to other studies, high creatinine levels at the time of transplantation increased the risk of death. ${ }^{53}$

As noted in the results, the risk of death after transplantation increased $0.6 \%$ for every hour of operative duration. This may be due to the complexity of the surgery which some studies have also suggested. ${ }^{11,17,43}$

Similar to the study by Roberts et $\mathrm{al},{ }^{27}$ in our research, if patients were admitted for hospitalization before surgery, they were $88 \%$ more likely to die than others. This could be due to the physical condition of patients, which is more fragile, and this situation usually persists after surgery and reduces patient survival.

The cold ischemic time had a significant effect on survival only in the univariate analysis; this finding was seen in some other studies, as well. ${ }^{17,35,42,58-60}$

Other variables, such as post-LT diabetes, waiting time to LT, Pre-OLT prothrombin time, history of alcohol consumption and pre-OLT comorbidity, existed in the final model but were not statistically significant.

Our study had some limitations. Overall, there are many genetic variables which can affect patient survival, but we did not consider them due to the retrospective nature of the study. Since almost all donors and recipients resided in the same region, often the northern part of Iran, it could be assumed that their genetic information matches, and has little influence on the final results.

Different individual characteristics, various clinical status, and unequal experience of physicians and centers lead to different findings in various studies. Therefore, caution should be taken when extrapolating our results to other LT patient populations.

From the statistical viewpoint, since heavy censoring 
existed at the end of the study (plateau form of KaplanMeier plots), and also, trend of AUC values decreased over time, our final model was not efficient in estimating the risk of mortality in the long-term. Thus, for estimating long-term survival (10 years and more), it is suggested to use more data or to apply advanced statistical models.

In conclusion, in 2000, TLTC started the LT program. In this study, we presented one of the largest reported singlecenter experiences with OLT in Iran. Many barriers have been overcome in this center to achieve high survival rates after LT; thus, it is expected that LT survivors can increase over the next decade. In summary, younger patients, cases with better health conditions before surgery and those without complications after OLT have superior posttransplantation survival. Furthermore, there is variability in the survival of patients with different underlying liver diseases.

\section{Authors' Contribution}

EM designed the study, performed statistical analysis, and wrote the manuscript; MM performed statistical analysis and revised the final version of the manuscript; MNT conducted data collection and revised the final version of the manuscript; TB performed statistical analysis and revised the final version of the manuscript; $\mathrm{HZ}$ designed the study and concept and revised the final version of the manuscript. All authors read and approved the final manuscript.

\section{Conflict of Interest Disclosures}

Mohssen Nassiri-Toosi is the chief of Liver Transplantation Research Center. The other authors report no proprietary or commercial interest in any product mentioned or concept discussed in this article.

\section{Ethical Statement}

The Ethics Committee of Tehran University of Medical Sciences approved this historical study (approval number: IR.TUMS.SPH. REC.1396.4825). The information of patients was de-identified prior to analysis.

\section{Availability of Data and Materials}

The datasets analyzed during the current study are available from the corresponding author on reasonable request.

\section{Funding Sources}

This research did not receive any specific grant from funding agencies in the public, commercial, or not-for-profit sectors.

\section{Acknowledgements}

We thank all recipients, donors, their families, and over 100 multidisciplinary teams who cooperate in the TLTC.

\section{References}

1. Olson JC, Kamath PS. Definitions, Epidemiology and Prognostication of Liver Disease. In: Nanchal R, Subramanian R, eds. Hepatic Critical Care. USA: Springer; 2018. doi: 10.1007/978-3-319-66432-3_7.

2. Institute for Health Metrics and Evaluation (IHME). GBD Compare Data Visualization. Seattle, WA: IHME, University of Washington, 2018. Available from: http://vizhub.healthdata. org/gbd-compare.

3. Starzl TE, Fung JJ. Themes of liver transplantation. Hepatology. 2010;51(6):1869-84. doi: 10.1002/hep.23595

4. National Institutes of Health Consensus Development Conference Statement: liver transplantation--June 20-23,
1983. Hepatology. 1984;4(1 Suppl):107S-110S.

5. Wiesner RH, Rakela J, Ishitani MB, Mulligan DC, Spivey JR, Steers JL, et al. Recent advances in liver transplantation. Mayo Clinic Proceedings. 2003;78(2):197-210.

6. Ratcliffe J, Longworth L, Young T, Bryan S, Burroughs A, Buxton $M$, et al. Assessing health-related quality of life pre-and postliver transplantation: a prospective multicenter study. Liver Transpl. 2002;8(3):263-70. doi:10.1053/jlts.2002.31345

7. Malek Hosseini SA, Lahsaee M, Zare S, Salahi H, Dehbashi $\mathrm{N}$, Firoozi MS, et al. Report of the first liver transplants in Iran. Transplant Proc. 1995;27(5):2618.

8. Global observatory on donation and transplantation. Available from:http://www.transplant-observatory.org/.

9. Macomber CW, Shaw JJ, Santry H, Saidi RF, Jabbour N, Tseng JF, et al. Centre volume and resource consumption in liver transplantation. HPB (Oxford). 2012;14(8):554-9. doi: 10.1111/j.1477-2574.2012.00503.x.

10. International Registry in Organ Donation and Transplantation. Available from: http://www.irodat.org/.

11. Hosseini SAM, Nikeghbalian S, Salahi H, Kazemi K, Shemsaeifar A, Bahador A, et al. Evolution of liver transplantation program in Shiraz, Iran. Hepat Mon. 2017;17(11):e60745. doi: 10.5812/hepatmon.60745.

12. Durand F. How to improve long-term outcome after liver transplantation? Liver Int. 2018;38 Suppl 1:134-138. doi: 10.1111/liv.13651.

13. Watt KD, Pedersen RA, Kremers WK, Heimbach JK, Charlton MR. Evolution of causes and risk factors for mortality post-liver transplant: results of the NIDDK long-term follow-up study. Am J Transplant. 2010;10(6):1420-7. doi: 10.1111/j.16006143.2010.03126.x.

14. Li J, Hansen BE, Peppelenbosch MP, De Man RA, Pan Q, Sprengers D. Factors associated with ethnical disparity in overall survival for patients with hepatocellular carcinoma. Oncotarget. 2017;8(9):15193-204. doi: 10.18632/ oncotarget.14771.

15. Pischke S, Lege MC, von Wulffen M, Galante A, Otto B, Wehmeyer $\mathrm{MH}$, et al. Factors associated with long-term survival after liver transplantation: A retrospective cohort study. World J Hepatol. 2017;9(8):427-435. doi: 10.4254/wjh. v9.i8.427.

16. Collett D, Friend PJ, Watson CJ. Factors associated with shortand long-term liver graft survival in the United Kingdom: development of a UK donor liver index. Transplantation. 2017;101(4):786-792. doi: 10.1097/TP.0000000000001576.

17. Pruinelli L, Monsen KA, Gross CR, Radosevich DM, Simon GJ, Westra BL. Predictors of liver transplant patient survival: A critical review using a holistic framework. Prog Transplant. 2017;27(1):98-106. doi: 10.1177/1526924816680099.

18. Bachir NM, Larson AM, Palmer BF. Adult liver transplantation in the United States. Am J Med Sci. 2012;343(6):462-9. doi: 10.1097/MAJ.0b013e3182308b66.

19. Donckier V, Lucidi V, Gustot T, Moreno C. Ethical considerations regarding early liver transplantation in patients with severe alcoholic hepatitis not responding to medical therapy. J Hepatol. 2014;60(4):866-71. doi: 10.1016/j. jhep.2013.11.015.

20. Gruttadauria S, Grosso G, Mistretta A, Pagano D, Scianna G, Vizzini GB, et al. Impact of recipients' socio-economic status on patient and graft survival after liver transplantation: the IsMeTT experience. Dig Liver Dis. 2011;43(11):893-8. doi: 10.1016/j.dld.2011.06.017.

21. Kamath PS, Wiesner RH, Malinchoc M, Kremers W, Therneau $\mathrm{TM}$, Kosberg $\mathrm{CL}$, et al. A model to predict survival in patients with end-stage liver disease. Hepatology. 2001;33(2):464-70.

22. Wiesner RH, McDiarmid SV, Kamath PS, Edwards EB, Malinchoc $M$, Kremers WK, et al. MELD and PELD: application of survival models to liver allocation. Liver Transpl. 
2001;7(7):567-80.

23. O'Leary JG, Lepe R, Davis GL. Indications for liver transplantation. Gastroenterology. 2008;134(6):1764-76. doi: 10.1053/j.gastro.2008.02.028.

24. Huo TI, Lin HC, Lee SD. Model for end-stage liver disease and organ allocation in liver transplantation: where are we and where should we go? J Chin Med Assoc. 2006;69(5):193-8. doi: 10.1016/S1726-4901(09)70217-5

25. Gheorghe L, Popescu I, lacob R, lacob S, Gheorghe C. Predictors of death on the waiting list for liver transplantation characterized by a long waiting time. Transpl Int. 2005;18(5):572-6. doi: 10.1111/j.1432-2277.2005.00090.x

26. Conn HO. A peek at the Child-Turcotte classification. Hepatology. 1981;1(6):673-6. doi: 10.1002/hep.1840010617

27. Roberts MS, Angus DC, Bryce CL, Valenta Z, Weissfeld L. Survival after liver transplantation in the United States: a disease-specific analysis of the UNOS database. Liver Transpl. 2004;10(7):886-97. doi: 10.1002/lt.20137

28. Rahimi-Dehkordi N, Nourijelyani K, Nasiri-Tousi M, GhodssiGhassemabadi R, Azmoudeh-Ardalan F, Nedjat S. Model for End stage Liver Disease (MELD) and Child-Turcotte-Pugh (CTP) scores: Ability to predict mortality and removal from liver transplantation waiting list due to poor medical conditions. Arch Iran Med. 2014;17(2):118-21.

29. Jafarian A, Nassiri-Toosi M, Najafi A, Salimi J, Moini M, Azmoudeh-Ardalan F, et al. Establishing a liver transplantation program at Tehran University of Medical Sciences, Iran: a report of ten years of experience. Arch Iran Med. 2014;17(1):81-3.

30. Kim WR, Lake JR, Smith JM, Schladt DP, Skeans MA, Harper AM, et al. OPTN/SRTR 2016 Annual Data Report: Liver. Am J Transplant. 2018;18 Suppl 1:172-253. doi: 10.1111/ajt.14559.

31. Klein JP, Van Houwelingen HC, Ibrahim JG, Scheike TH. Handbook of Survival Analysis. USA: CRC Press; 2016.

32. Collett D. Modelling Survival Data in Medical Research. UK: Chapman and Hall/CRC; 2015.

33. Neuberger J. Liver transplantation in the United Kingdom. Liver Transpl. 2016;22(8):1129-35. doi: 10.1002/lt.24462.

34. Adam R, Karam V, Cailliez V, O Grady JG, Mirza D, Cherqui D, et al. 2018 Annual Report of the European Liver Transplant Registry (ELTR)-50-year evolution of liver transplantation. Transpl Int. 2018;31(12):1293-1317. doi: 10.1111/tri.13358.

35. Agopian VG, Petrowsky H, Kaldas FM, Zarrinpar A, Farmer DG, Yersiz $\mathrm{H}$, et al. The evolution of liver transplantation during 3 decades: analysis of 5347 consecutive liver transplants at a single center. Ann Surg. 2013;258(3):409-21. doi: 10.1097/ SLA.0b013e3182a15db4.

36. Schoening WN, Buescher N, Rademacher S, Andreou A, Kuehn $S$, Neuhaus R, et al. Twenty-year longitudinal follow-up after orthotopic liver transplantation: a single-center experience of 313 consecutive cases. Am J Transplant. 2013;13(9):2384-94. doi: 10.1111/ajt.12384.

37. Su F, Yu L, Berry K, Liou IW, Landis CS, Rayhill SC, et al. Aging of liver transplant registrants and recipients: trends and impact on waitlist outcomes, post-transplantation outcomes, and transplant-related survival benefit. Gastroenterology. 2016;150(2):441-53.e6. doi: 10.1053/j.gastro.2015.10.043.

38. Lipshutz GS, Hiatt J, Ghobrial RM, Farmer DG, Martinez $\mathrm{MM}$, Yersiz $\mathrm{H}$, et al. Outcome of liver transplantation in septuagenarians: a single-center experience. Arch Surg. 2007;142(8):775-81. doi: 10.1001/archsurg.142.8.775

39. Aduen JF, Sujay B, Dickson RC, Heckman MG, Hewitt WR, Stapelfeldt $\mathrm{WH}$, et al. Outcomes after liver transplant in patients aged 70 years or older compared with those younger than 60 years. Mayo Clin Proc. 2009;84(11):973-8. doi: 10.1016/S0025-6196(11)60667-8.

40. Starzl TE, Todo S, Gordon R, Makowa L, Tzakis A, Iwatsuki $S$, et al. Liver transplantation in older patients. N Engl J Med. 1987;316(8):484-5.
41. Braat AE, Blok JJ, Putter H, Adam R, Burroughs AK, Rahmel $A O$, et al. The Eurotransplant donor risk index in liver transplantation: ET-DRI. Am J Transplant. 2012;12(10):278996. doi: 10.1111/j.1600-6143.2012.04195.x.

42. Busuttil RW, Farmer DG, Yersiz H, Hiatt JR, McDiarmid SV, Goldstein LI, et al. Analysis of long-term outcomes of 3200 liver transplantations over two decades: a single-center experience. Ann Surg. 2005;241(6):905-16; discussion 916-8. doi: 10.1097/01.sla.0000164077.77912.98

43. Filali Bouami S, Gwiasda J, Beneke J, Kaltenborn A, Liersch S, Suero EM, et al. Prognostic factors for long-term survival after adult liver transplantation. Langenbecks Arch Surg. 2018;403(4):495-508. doi: 10.1007/s00423-018-1670-5.

44. Ilyas JA, O'Mahony CA, Vierling JM. Liver transplantation in autoimmune liver diseases. Best Pract Res Clin Gastroenterol. 2011;25(6):765-82. doi: 10.1016/j.bpg.2011.09.008.

45. Singal AK, Chaha KS, Rasheed K, Anand BS. Liver transplantation in alcoholic liver disease current status and controversies. World J Gastroenterol. 2013;19(36):5953-63. doi: $\quad$ 10.3748/wjg.v19.i36.5953.

46. Dawwas MF, Gimson AE, Lewsey JD, Copley LP, van der Meulen JH. Survival after liver transplantation in the United Kingdom and Ireland compared with the United States. Gut. 2007;56(11):1606-13.

47. Sterneck M, Huebener P, Bangert K, Drolz A, Kluge S, Lohse $A$,et al. Predictors for post transplant survival in patients with acute-on-chronic liver failure. Transplantation 2018;102:S417.

48. Faisal N, Renner EL. Recurrence of autoimmune liver diseases after liver transplantation. World J Hepatol. 2015;7(29):2896905. doi: 10.4254/wjh.v7.i29.2896.

49. Wei Q, Nemdharry RS, Zhuang RZ, Li J, Ling Q, Wu J, et al. A good prognostic predictor for liver transplantation recipients with benign end-stage liver cirrhosis. Hepatobiliary Pancreat Dis Int. 2017;16(2):164-168. doi: 10.1016/s14993872(16)60187-x

50. Huo TI, Lin HC, Wu JC, Hou MC, Lee FY, Lee PC, et al. Limitation of the model for end-stage liver disease for outcome prediction in patients with cirrhosis-related complications. Clin Transplant. 2006;20(2):188-94. doi: 10.1111/j.13990012.2005.00463.x

51. Cywinski JB, Mascha EJ, You J, Sessler DI, Kapural L, Argalious $M$, et al. Pre-transplant MELD and sodium MELD scores are poor predictors of graft failure and mortality after liver transplantation. Hepatol Int. 2011;5(3):841-9. doi: 10.1007/ s12072-011-9257-z.

52. Patkowski W, Zieniewicz K, Skalski M, KrawczykM. Correlation between selected prognostic factors and postoperative course in liver transplant recipients. Transplant Proc. 2009;41(8):3091102.doi:10.1016/j.transproceed.2009.09.038.

53. Aloia TA, Knight R, Gaber AO, Ghobrial RM, Goss JA. Analysis of liver transplant outcomes for United Network for Organ Sharing recipients 60 years old or older identifies multiple model for end-stage liver disease-independent prognostic factors. Liver Transpl. 2010;16(8):950-9. doi: 10.1002/ It.22098.

54. Agarwal S, Joyner Jr KA, Swaim MW. Ascites fluid as a possible origin for hyperfibrinolysis in advanced liver disease. Am J Gastroenterol. 2000;95(11):3218-24. doi: 10.1111/j.15720241.2000.03299.x

55. Spadaro A, Tortorella V, Morace C, Fortiguerra A, Composto $\mathrm{P}$, Bonfiglio $\mathrm{C}$, et al. High circulating D-dimers are associated with ascites and hepatocellular carcinoma in liver cirrhosis. World J Gastroenterol. 2008;14(10):1549-52. doi: 10.3748/ wjg.14.1549

56. Haugaa H, Taraldsrud E, Nyrerød HC, Tønnessen TI, Foss A, Solheim BG. Low incidence of hyperfibrinolysis and thromboembolism in 195 primary liver transplantations transfused with solvent/detergent-treated plasma. Clin Med 
Res. 2014:12(1-2):27-32. doi: 10.3121/cmr.2013.1168.

57. Horvatits T, Pischke S, Proske VM, Fischer L, Scheidat S, Thaiss $\mathrm{F}$, et al. Outcome and natural course of renal dysfunction in liver transplant recipients with severely impaired kidney function prior to transplantation. United European Gastroenterol J. 2018;6(1):104-111. doi: 10.1177/2050640617707089.

58. DiNorcia J, Lee MK, Harlander-Locke M, Zarrinpar A, Kaldas FM, Yersiz H, et al. Reoperative complications after primary orthotopic liver transplantation: a contemporary single-center experience in the post-model for end-stage liver disease era. J Am Coll Surg. 2014;219(5):993-1000. doi: 10.1016/j. jamcollsurg.2014.07.005.

59. Jochmans I, Fieuws S, Tieken I, Samuel U, Pirenne J. The impact of implantation time during liver transplantation on outcome: a eurotransplant cohort study. Transplant Direct. 2018;4(6):e356. doi: 10.1097/TXD.0000000000000793.

60. Pan ET, Yoeli D, Galvan NTN, Kueht ML, Cotton RT, O'Mahony $\mathrm{CA}$, et al. Cold ischemia time is an important risk factor for post-liver transplant prolonged length of stay. Liver Transpl. 2018;24(6):762-768. doi: 10.1002/lt.25040. 